\title{
Why didn't Darwin discover Mendel's laws?
} Jonathan C Howard

Address: Institute for Genetics, University of Cologne, Zülpicher Strasse 47, 50674 Cologne, Germany. Email: j.howard@uni-koeln.de

Published: 24 February 2009

Journal of Biology 2009, 8: 15 (doi:10.1 186/jbiol I23)

The electronic version of this article is the complete one and can be found online at http://jbiol.com/content/8/2/15

(c) 2009 BioMed Central Ltd

\author{
Abstract \\ Darwin's focus on small quantitative variations as the raw material of evolution may have \\ prevented him from discovering the laws of inheritance.
}

Heredity and variation were two concepts that played a central role in Darwin's development of the theory of evolution by natural selection. The enormous effort he devoted to their analysis is reflected not only in the entire two-volume The Variation of Animals and Plants under Domestication [1], but also in countless experiments and observations narrated elsewhere. Yet despite a lifetime's efforts, he never came close to understanding the logic of inheritance, while his views on the nature and causation of variation oscillated back and forth between a concept of random, quasi-physical events outside environmental control, which indeed looks decidedly modern, and a concept, evidently owing much to his predecessors, of environmentally driven adaptive change transmitted to the germ cells. Here, I ask why Darwin failed, even after so much effort, to reach a correct position on these critical problems. The solution, at least to the inheritance problem, was apparently easily amenable to an experimental approach with materials that were daily to hand. Furthermore the time was ripe in the middle of the 19th century, with many breeders interested in the problem for commercial as well as scientific reasons. And after all, Mendel (Figure 1) solved the logic of inheritance in his own backyard in the monastery at Brno [2] with no more technology than Darwin had at his disposal in his garden at Down House. Why couldn't Darwin have done it too?

There is a plausible answer to this question that has a very long reach, far into the 20th century, namely Darwin's commitment to quantitative variation as the raw material of evolution. There were surely also other contributing issues that turned him away from the kind of investigations that would have led him to the answer. One was that inheritance as such was really not a controversial issue. Even though he needed inheritance as a key player in the theory of evolution by natural selection ("Any variation which is not inherited is unimportant for us" [3] p12) he could appeal to the general belief system, which upheld the constancy of species, while at a more professional level he asserted "No breeder doubts how strong is the tendency to inheritance: that like produces like is his fundamental belief" ([3] p12) and he summarizes his position with "perhaps the correct way of viewing the whole subject would be, to look at the inheritance of whatever character as the rule, and noninheritance as the anomaly" ([3] p13). Thus, in a sense, the heritability of a character could be treated as a given for the purposes of the general exposition of the theory of evolution by natural selection.

\section{Pigeons and snapdragons}

Since the rediscovery of Mendel we have become used to the principle of working with unit factors of qualitative effect as if they represented explicit, patent instances of the kinds of variation that have evolutionary implications. Now that every variation, whether of large or small effect, can be followed by simple Mendelian genetics using the underlying sequence changes, the difference between 'qualitative' 


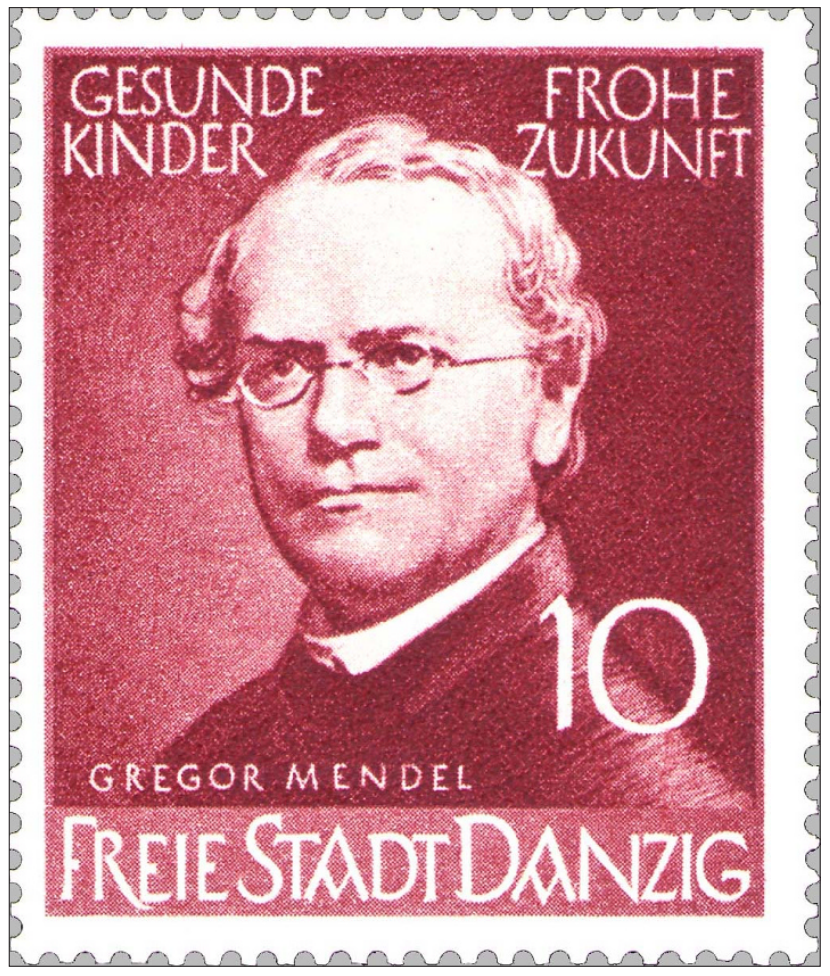

Figure I

Gregor Mendel: a commemorative stamp issued by the Free City of Danzig in 1939. The texts above the picture read "Healthy children" and "Happy future".

and 'quantitative' characters has been lost for many purposes. Darwin was ambivalent about visible, discontinuous variations. They displayed the phenomena of inheritance in an immediately appreciable form, but under the conditions in which, until Mendel, such variation was studied, even the behavior of apparently 'unit' characters through the generations was too obscure to make sense. In particular, many of the variations that attracted Darwin's interest had been accumulated through horticultural or agricultural selective breeding and were recessive to the wild type. From Darwin's standpoint the loss of recessive phenotypes in test crosses and, even more striking, the recovery of the wild type in crosses between non-allelic recessives, had polemical value in enabling wild ancestry to be claimed even for the phenotypically extreme products of selective breeding (Figure 2). Those who supported the fixity of species were skeptical that fancy pigeons with radically distinct phenotypes could have been derived from a single wild ancestral species. Yet Darwin could win the argument dramatically by crossing two such fancy strains and generating progeny with a perfect wild rock dove phenotype. Furthermore, in the absence of pure lines distinguished by single unit characters, the simple behavior of the F1 hybrid between two different phenotypes was often confused by the behavior of subsequent generations, in which multiple polymorphic systems read out onto the complex character of interest (Figure 3). Despite the polemical value of some aspects of discontinuous character inheritance, therefore, Darwin's conclusion from his studies on inheritance was always the same, that the rules and mechanisms of inheritance were complex and not ready for a definitive analysis.

Mendel's extraordinary insight into the simplifications necessary to extract sense from his breeding program would also have been necessary for Darwin were he to have taken up the challenge seriously. We can discount almost everything that Darwin did or said about inheritance because he lacked Mendel's insight and failed to recognize what was wrong with his material. But we cannot discount it all. In his pursuit of a better understanding of the importance of cross-breeding for evolution he reported many instances in which heritable unit characters showed what to our eyes can be understood as Mendelian behavior. In one especially poignant case [1], working with the recessive character of radially symmetrical (peloric) flowers of Antirrhinum (Figure 4), Darwin came close to the kind of result that might have ended with a law of segregation. He crossed pure-breeding peloric plants with pure breeding wild types, noting the dominance of the wild type in the F1 progeny. He then established the F2 generation and obtained wild-type and peloric plants in a ratio (88:37) that Mendel (and now we) would effortlessly accept as representing 3:1. However, Darwin had other priorities and was in no way programmed to see the critical meaning in these numbers. He cites them within a sentence and they receive no further comment.

What, if it wasn't genetics, was Darwin doing in his study The Effects of Cross and Self-Fertilisation in the Vegetable Kingdom [4]? His overriding purpose was to establish that progeny produced by self-fertilization are less thrifty than the products of cross-fertilization. He rightly concentrated his analysis not on unit characters, but on the quantitative characters that fitted better with his concept of differential fitness, the attributes that, by their infinitesimal differences, determine life and death in the wild. So Darwin counted seeds, weighed and measured them, planted them and looked for their vitality. He measured growth and general thriftiness in his self-fertilized and cross-fertilized progeny. Everything he measured was a quantitative variable that under these simple experimental conditions could yield no information about inheritance at all. His experiments are overwhelming in scale and scope; they established the point that he wanted to establish beyond all doubt, but they contributed nothing relevant to our understanding of the underlying logic of inheritance. 


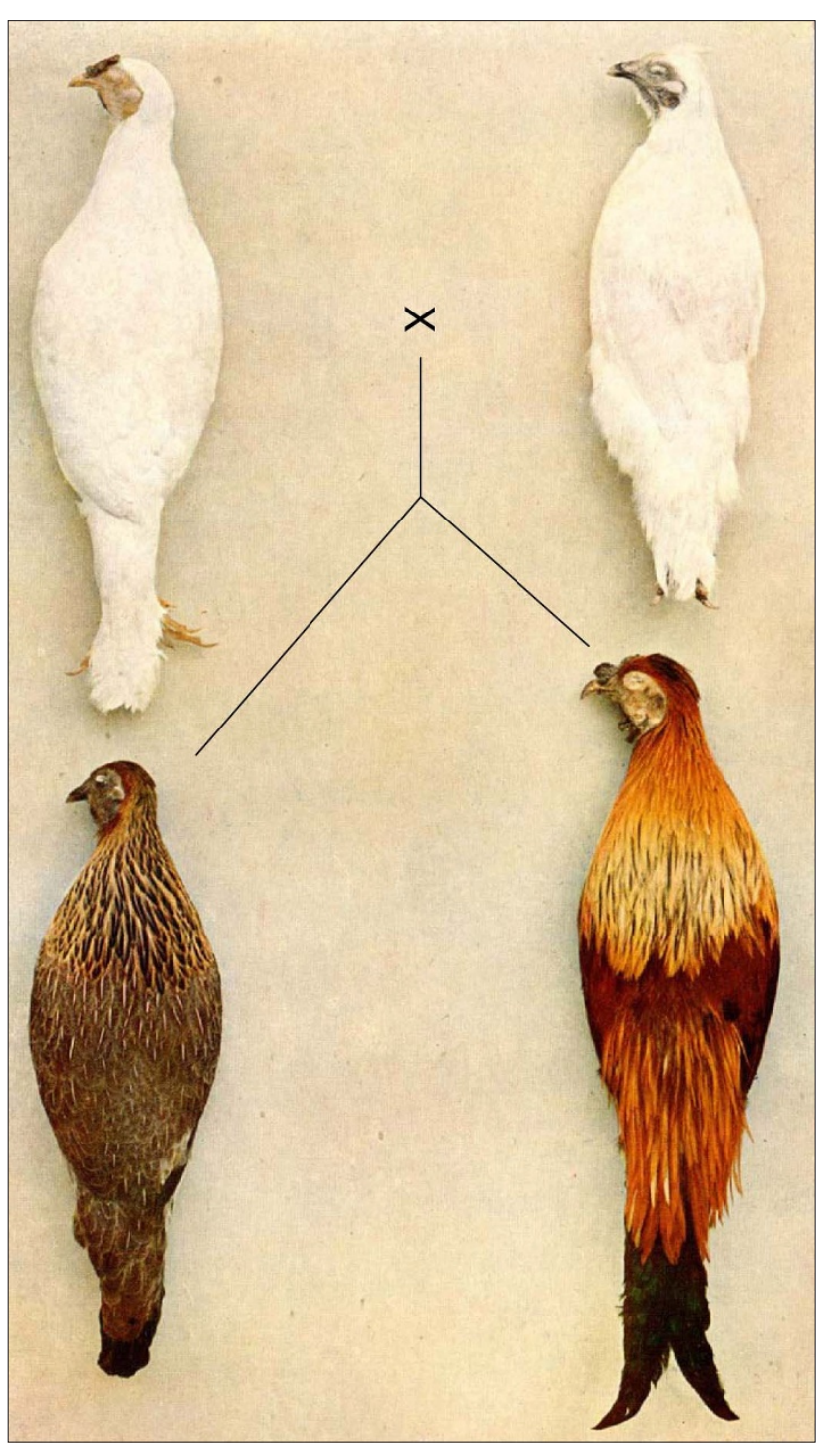

Figure 2

Reversion to the ancestral type. Two non-allelic, recessive white mutants in domestic fowl (top) complement each other to generate perfect wild-type male (bottom right) and female (bottom left) progeny. Reversion was of polemical value for Darwin in indicating that highly divergent domesticated stocks had been derived from a single ancestral species, but contributed to the widespread confusion over the laws of inheritance. From [16] plate 4 between pages 100 and 101.

\section{The forms of flowers}

The reader who seeks Mendelian impulses in Darwin's work will be disappointed with the yield of such insights in Cross and Self-Fertilisations and turn to The Different Forms of Flowers on Plants of the Same Species [5]. Here Darwin wrote an entire book on a perfect Mendelian character showing unambiguous phenotypes and numerically precise and well-established behavior, yet he failed to extract Mendelian insights from his work. The Different Forms of Flowers is devoted to various cases of heterostyly, the best known being the beautiful floral dimorphisms of various species of Primula (Figure 5). It was well known, and confirmed in Darwin's studies, that crosses between individuals each bearing flowers of one of the two floral types were fertile and generated the two floral types in the progeny equally. Modern Mendelians can recognize the character of such a result as a form of back-cross between a heterozygote bearing one dominant allele and one recessive and a homozygote bearing two recessive alleles at the locus, the same inheritance pattern as in many sex-determination systems. And indeed Darwin was exploring these phenomena precisely because he recognized that these di- (and elsewhere tri-)morphic floral systems were dedicated to the enforcement of cross-fertilization.

The floral dimorphism of Primula is determined by a complex locus encoding three closely linked genes that determine the floral type. In elementary inheritance studies this 'supergene' segregates as a single locus. Unlike the case with our own XY sex-determination system, which behaves genetically in a similar way, the two floral forms of Primula possess both male and female organs and are not absolutely self-sterile. Thus it is possible to dissect the underlying genetics (at least at the level of the complex locus) by examining the floral morphology of, albeit rare, progeny from a successful self-cross. But Darwin barely did this. His mission was accomplished by documenting the degree of self-sterility measured by seed number and weight. He planted the seeds of self-fertilized plants and measured their own thriftiness by quantitative analysis, but his reports on the floral morphology of the self-fertilized progeny are sketchy. However, he did show that the 'pin' (homozygous recessive) form breeds true whereas the heterozygous 'thrum' form has both thrum and pin forms in the progeny, with an apparent excess of thrums, results consistent with the now-known genetics of the system. Darwin summarized his own results on the inheritance of floral morphology in illegitimate crosses in a table, and cited data, not his own, on illegitimate thrum crosses in Primula auricula with the statement shown in Figure 6, a remarkable statement given that it appears to be a numerical approximation to a Mendelian ratio. It would be interesting to find out from what source these data came: it is probably already known and I should be glad to learn. In a letter to Alfred Russel Wallace in 1866 [6] Darwin also drew attention to the generation of both unblended parental forms "even out of the same pod" in crosses between two varieties of sweet pea, presumably among an F2 progeny, but he did not comment on the relative yields. He did, however, see a similarity between this kind of genetic behaviour and sex determination when he added that the former were not more wonderful 


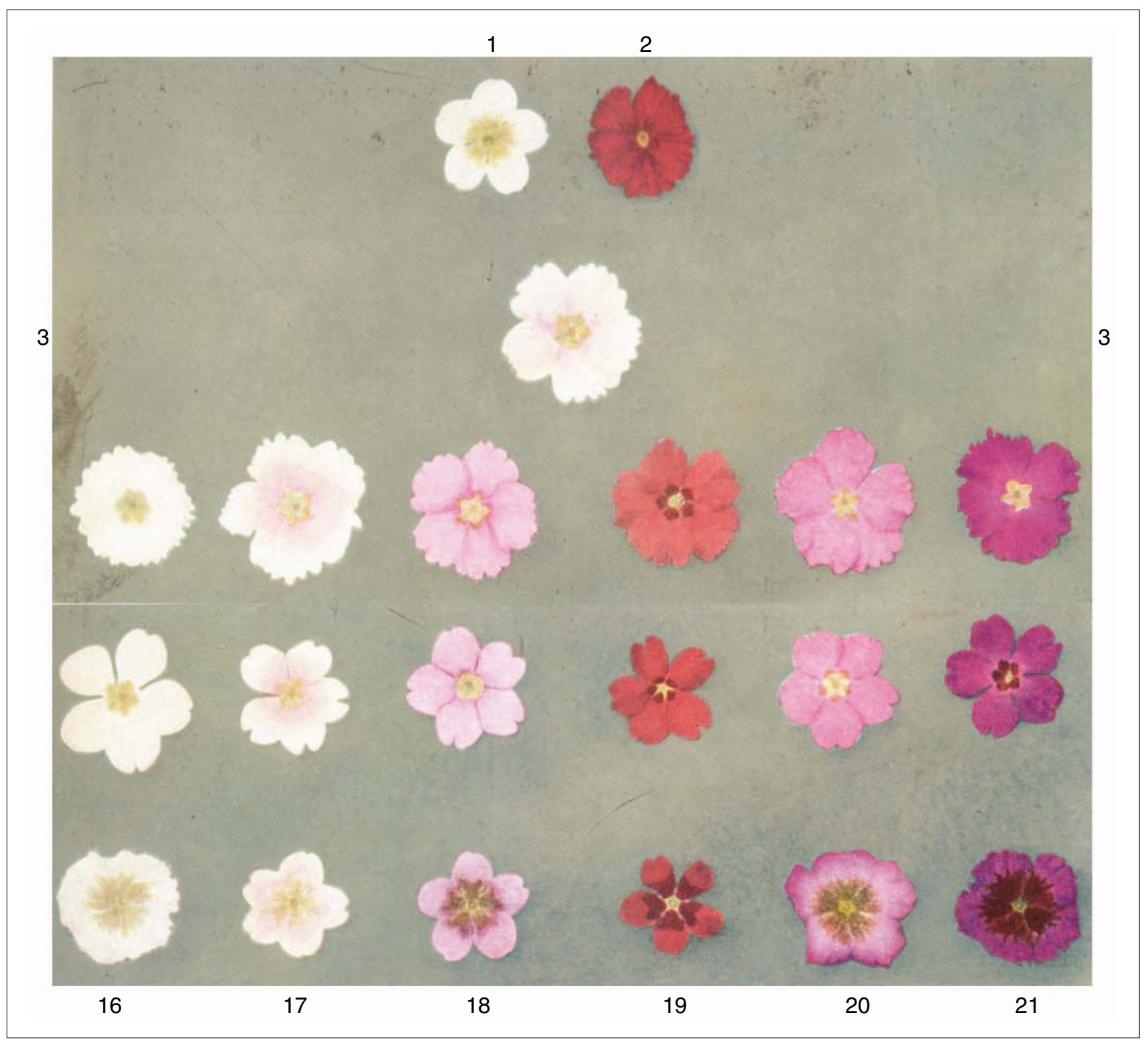

\section{Figure 3}

Fragmentation of a qualitative character in Primula sinensis. The FI (3) of a cross between the two parental varieties ( $\mathrm{I}$ and 2$)$ is constant and somewhat intermediate in character, although white. The F2 progeny (bottom three rows) are highly variegated, atomizing the overall phenotypic difference between the two parents into a remarkable number of distinct traits. Phenomena like this bedeviled the efforts of many breeders, until Mendel, to find simple laws of inheritance. From [16] plate 7 between pages 298 and 299.

"than every female in the world producing distinct male \& female offspring"."

\section{Infinitesimals}

Obviously Darwin was not on the right wavelength to be able to use inheritance data from crosses involving unit characters. Why not? The material was there and the problem of inheritance was patently unsolved and important. Much has been written, and with justice, of Mendel's extraordinary preadaptation to solving the problem he so precisely set himself: his mathematical bent, and his education in biology, physics, statistics and probability theory [7] that was far superior to anything Darwin could have got in a British university. Even if Darwin had decided to press on with his Antirrhinum or Primula studies he 
perhaps would not have seen through the stochasticity of the experimental results to the whole numbers that were waiting to be discovered. The explanation, though, for why Darwin turned away from the inheritance of unit characters as a possible route to resolving the general inheritance problem was simply that he did not believe that such characters had anything to do with the kind of variations that he thought were the raw materials of evolutionary change. Such qualitative and striking variations he characterized as 'sports'. They might be useful for the breeders of fancy plants and animals, but although artificial selection of such anomalous variants could provide an analogy to evolution by natural selection, this was not the real thing. Again and again, when Darwin wrote generally about evolution, he came back to one issue, the infinitely tiny differences between individuals that confer infinitesimal advantages or disadvantages in the interminable struggle for existence. The selection of these variants, continued over hundreds of thousands of generations, was the critical process in evolution. These were the variations, and this was the inheritance, that mattered. This view of biology was uniquely Darwin's and one he took over wholesale from Charles Lyell's uniformitarian geology during and after the Beagle voyage. Indeed this was by far the strongest, most important, and heuristically most productive of all the influences Darwin was subject to ("I always feel as if my books came half out of Lyell's brain" [8]). Uniformity of small actions over long time gave Darwin much of his geology and above all his exquisite theory of coral reefs. It also gave him evolution.

Darwin's commitment to the finest possible grain of quantitative variation is so explicit in his writing that it is impossible to doubt its importance for him. One can find dozens of passages like the last sentence of Darwin's early sketch [9]: "There is a simple grandeur in this view of life... having been breathed into matter under a few forms, perhaps only one,... and that from so simple an origin, through the selection of infinitesimal varieties, endless forms most beautiful and most wonderful have been evolved", or "If selection consisted merely in separating some very distinct variety, and breeding from it, the principle would be so obvious as hardly to be worth notice; but its importance consists in the great effect produced by the accumulation in one direction, during successive generations, of differences absolutely inappreciable to the uneducated eye - differences which I for one have vainly attempted to appreciate" ([3] p32), or "It may be said that natural selection is daily and hourly scrutinising, throughout the world, every variation, even the slightest: rejecting that which is bad, preserving and adding up all that is good" ([3] p84), or, lastly, "Natural selection can act only by the preservation and accumulation of infinitesimally small inherited modifications, each

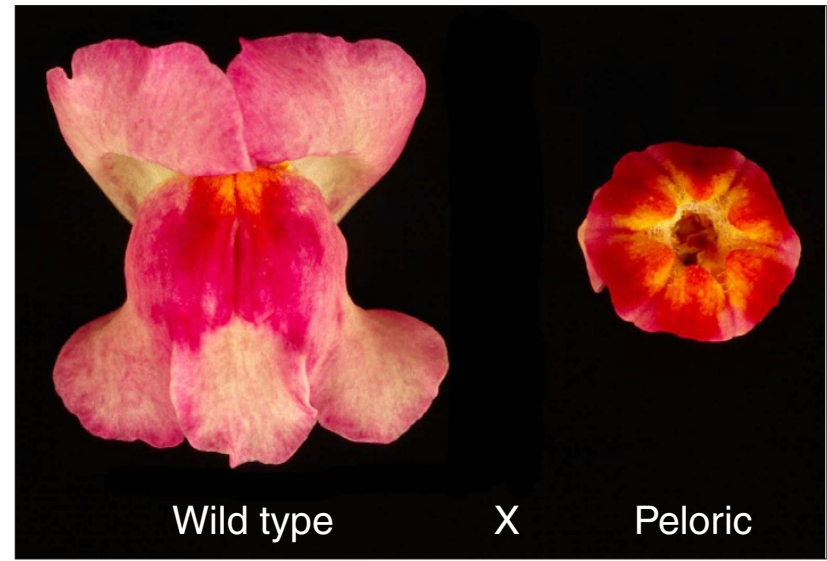

Figure 4

Wild-type and peloric flowers of Antirrhinum majus. Darwin noted the near-complete dominance of the wild type and the segregation of the recessive allele in the $\mathrm{F} 2$. This is a floral trait determined by a single recessive allele and could have given Darwin the Mendelian ratios if he had pursued his breeding experiments. Photograph kindly provided by and copyright Enrico Coen. Reproduced with permission.

profitable to the preserved being; and as modern geology has almost banished such views as the excavation of a great valley by a single diluvial wave, so will natural selection, if it be a true principle, banish belief in the continued creation of new organic beings, or of any great and sudden modification in their structure." ([3] p95).

Quantitative variation, then, was at the heart of Darwin's evolution, and quantitative variation is the last place where clean Mendelian inheritance can be seen, Look at the difficulties! All quantitative variation is determined by multiple allelic systems of small effect. Furthermore, quantitative variation shows the greatest sensitivity to environmental variables. Finally, many characters that show complex quantitative inheritance are also subject to genetically determined adaptability, such as skin color or muscle mass. This last was indeed Darwin's undoing when he attempted to construct a general theory of variation and inheritance, the 'Provisional Hypothesis of Pangenesis' ([1], Chapter XXVII). It was responsible for his persistent belief in the inheritance of acquired characters and determined much of the design of the pangenesis theory.

\section{Pangenesis}

When he embarked on the 'Provisional Hypothesis of Pangenesis' [1] it was the behavior of continuously variable characters that Darwin set out to account for. This widely unloved hypothesis was a great favorite of Darwin's and the only time when he ventured into the domains we would 


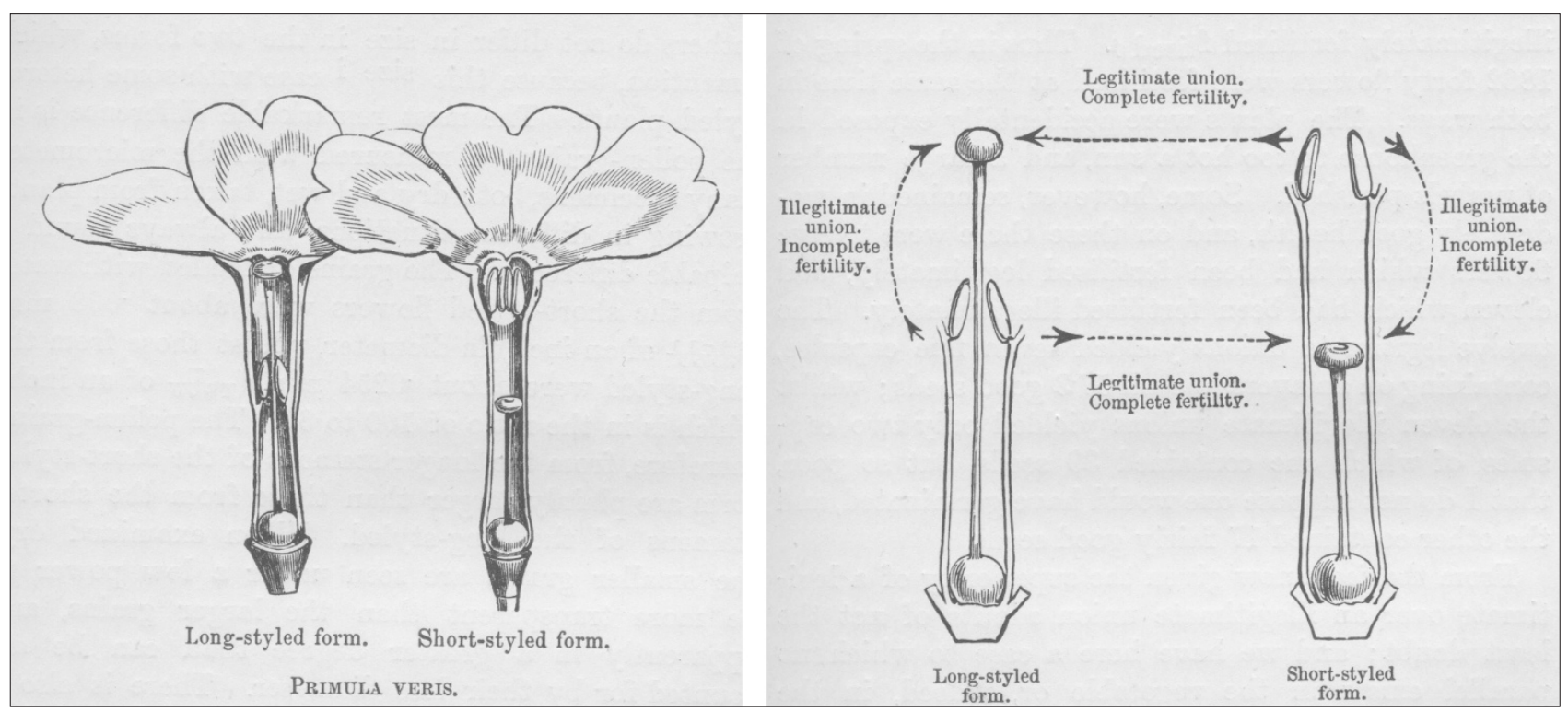

Figure 5

Drawings taken from Darwin's The Different Forms of Flowers on Plants of the Same Species [5], illustrating the clear morphological distinction between the two floral types of Primula flowers. The 'thrum' (short-styled) form is determined by a dominant 'supergene' in the heterozygous state, the 'pin' (long-styled) form by the homozygous recessive. Thrum and pin forms are maintained in roughly equal numbers by the high fertility of thrum $x$ pin crosses and near infertility of the two illegitimate thrum $x$ thrum and pin $x$ pin crosses. Although Darwin worked extensively on this beautiful qualitative trait, his interest was focused on the quantitative deficit of illegitimate progeny rather than the genetic control of the trait itself.

now call cell biology and biochemistry. Hampered already by his focus on quantitative variation and, like most British biologists, unconvinced by the contemporary German triumph of cell theory, Darwin was in no position to get it right. He conceived of tiny self-replicating determinants representing all characters at the finest possible level of discrimination. If an organ looks thus, so its pangenetic representation will be such as to determine such an appearance. If an organ is large, small, long, or short, each characteristic parameter can be measured by the number of pangenes that determine it. Inheritance of such a character follows from the collection, according to exact proportional representation, of all possible pangenes from all parts of the body into the germ cells; a heavier muscle, then more pangenes for each relevant component, and a higher representation of each in the germ cells. Every aspect of phenotype was covered by appropriate pangenes, even the left and right halves of the body were separately determined.

Much of Darwin's representation of the pangenesis hypothesis concerns measurable quantitative characters, such as muscle mass, for which it was straightforward to relate variations in some parameter, such as size or weight, with the number of the relevant pangenes. Obsessed as he was by the infinitesimal character of variation, Darwin took a lot of trouble to convince his readers that pangenes were so extremely small that all necessary pangenes would fit into the critical smallest compartment, namely the germ cells. Even here, Darwin was far less confident than Mendel that one sperm and one egg constituted the essential minimum. Nevertheless, supported by a calculation from his mathematically gifted son George, Darwin convinced himself that molecular sizes were tiny enough for him to pack all the pangenes he needed into the compass of a single fertilized egg or sperm.

One can follow the internal logic of pangenesis and see that it is preadapted to be a theory of continuous, not discontinuous, variation. Saddled with his infinitesimal variations, Darwin was driven by the pangenesis theory in a direction he never seems to have been totally averse from, namely the inheritance of acquired characters. If the adaptability of the soma generated adaptive change, as the blacksmith's muscles, so more muscle pangenes were needed to account for the extra muscles and would consequently be overrepresented in the germ cells. Darwin's view of inherited variation was complex, and the inheritance of acquired characters was only one strand in an unresolved tangle of ideas. But it dominates the pangenesis hypothesis and one may suppose that Darwin's (largely unshared) affection for his own hypothesis was responsible for a trend, noted by many commentators, towards favoring the significance of this 


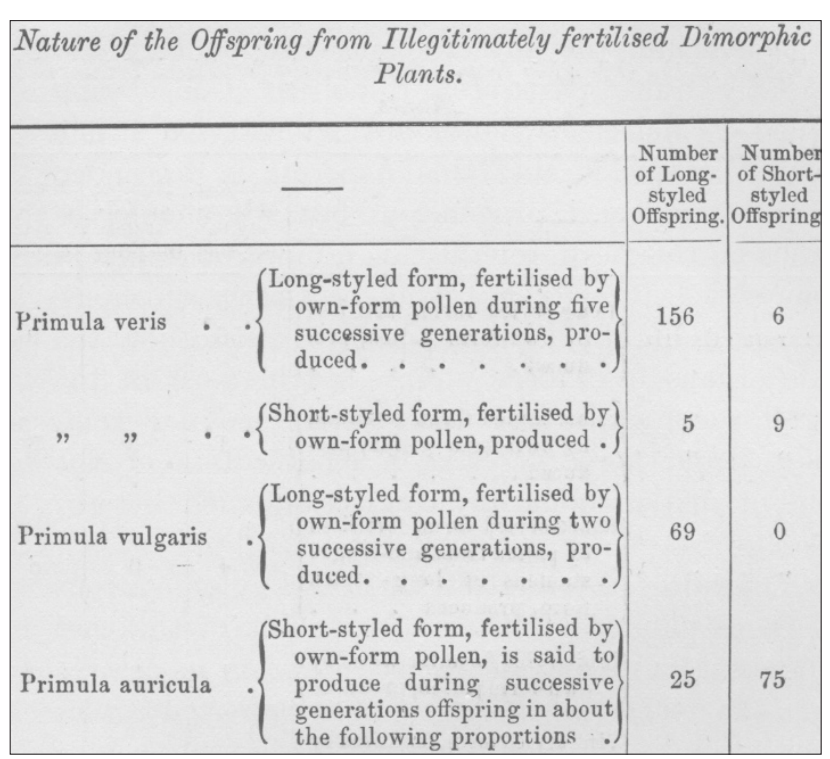

\section{Figure 6}

Darwin's table summarizing the results of Primula crosses. Note especially the last line referring to the Primula auricula data, where the recessive and dominant forms respectively are cited as occurring in a I:3 ratio in crosses between heterozygous dominant (short-styled) individuals. Reproduced from [5].

kind of evolutionary change in the later editions of On the Origin of Species. Unlike the great bulk of Darwin's original ideas, pangenesis, published in 1868 [1], is a latecomer, not foreshadowed in his earlier notebooks and essays.

\section{From Galton and Bateson to Gould}

Darwin is occasionally criticized as an imprecise, nonnumeric naturalist, a man of ideas, perhaps brilliant and original in that mode, but not a scientist like those of today. Indeed I am sure I have heard this view from eminent members of my own institute. Mendel's rational, experimental analysis of the inheritance of unit characters is without question a work of great genius. One reads it still with the same sense of breathless excitement, of irresistible intellectual force and forward propulsion that one experiences, for example, from the extraordinary Nature paper by Crick, Brenner, Barnett and Watts-Tobin on the encoding of proteins [10]. However, if Darwin failed to discover Mendel's laws, it was not so much because of what he lacked in genius or numeracy or the experimental cast of mind, but rather because of the forceful tendency of what he already possessed. His focus on continuous variation as the source of evolutionary change was not wrong, and coupled with the power he could see in the integration of infinitesimals over time he built his case on the solid foundation of Lyell's uniformitarian thinking. Much of variation and inheritance was simply opaque in those terms, but continuous variation, not unit characters, was, for Darwin, the way forward. Thus Darwin boxed himself in, unable to see the laws of inheritance in continuous variation, unable to see the real importance of discontinuous variation where the laws of inheritance could be discerned.

The scientist in the best position to resolve Darwin's problems was his own cousin, Francis Galton (Figure 7). While Darwin was wrestling with pangenesis Galton was pioneering the analysis of the inheritance of quantitative characters and he documented with extraordinary insight the properties of such inheritance. In particular, he documented the phenomenon of regression to the mean in the context of the inheritance of quantitative characters such as height or intelligence. Regression to the mean records the interaction between control of the character by multiple polymorphic loci of small effect and, of course, multiple environmental effects. Galton approached a correct genetic interpretation of this phenomenon while Darwin confused it with blending inheritance. He also took a lively interest in pangenesis (which he eventually rejected, to Darwin's chagrin) and corresponded extensively with Darwin about it. In a somewhat gnomic response to a query from Darwin, Galton replied "If there were two gemmules only, each of which might be white or black, then in a large number of cases one-quarter would always be quite white, one-quarter quite black, and one half would be grey". Such is indeed the stuff of continuous variation seen from a Mendelian perspective, but perhaps Galton was too distant from the biology of inheritance and too interested in the mathematics of what he was discovering to take his own suggestion to its most important conclusion.

Galton died in 1911, a full decade after the multiple republications of Mendel's paper and multiple reiterations of his findings by other authors. It is surprising that Galton in his old age did not take the opportunity, which he of all geneticists of that era was qualified to take, to reconcile the Mendelian laws of inheritance with Darwin's (and his own) priority for continuous variation as the fuel of evolutionary change. In the event, most of Galton's contemporaries largely abandoned Darwin's view in favor of mutations of large effect as the driving force for evolutionary change. William Bateson, in his 1894 Materials for the Study of Variation [11], had already backed large-scale discontinuous variation as the basis for evolution and the origin of species, "for if distinct and 'perfect' varieties may come into existence 


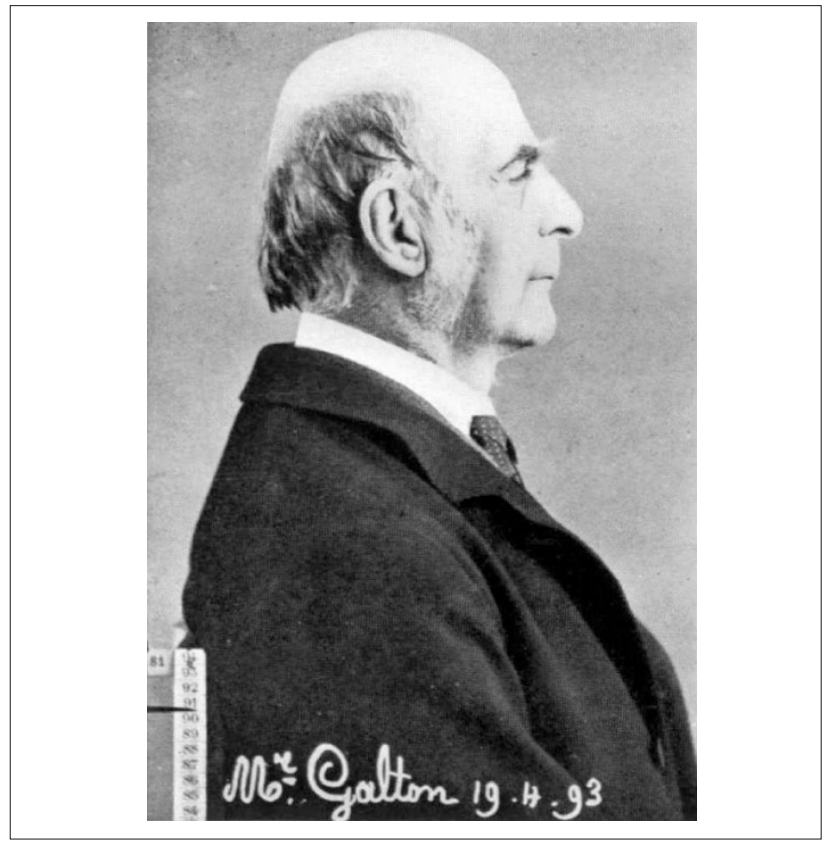

Figure 7

Francis Galton, the anthropometrician, in 1893. Reproduced from an anthropometric study cited in [17].

discontinuously, may not the Discontinuity of Species have had a similar origin? If we accept the postulate of Common Descent this expectation is hard to resist. In accepting that postulate it was admitted that the definiteness and Discontinuity of Species depends upon the greater permanence of certain terms in the series of Descent. The evidence of Variation suggests that this greater stability depends primarily not on a relation between organism and environment, not, that is to say, on Adaptation, but on the Discontinuity of Variation. It suggests, in brief, that the Discontinuity of Species results from the Discontinuity of Variation." Elsewhere, the sneering tone of Bateson's concluding remarks on adherents of the Darwinian view suggests the ill-humor that accompanied this debate right through until the late 1920s, when Fisher, Haldane, Sewall Wright and others reconciled Mendelism with continuous variation (reviewed in [12]). Hugo de Vries, whose own studies of discontinuous variation led him to the rediscovery of Mendel, also argued [13] for variation of large effect as the driving force in evolution, and even as late as the 1930s this strand of thought was still prominent in Richard Goldschmidt's 'hopeful monsters' [14]. The old dichotomy between continuous and discontinuous variation as the engines of evolution surfaced again in a slightly different form in our own generation through the polemic of Niles Eldredge and Stephen J Gould for evolution by punctuated equilibrium [15]. No doubt we shall see it again.

\section{Acknowledgements}

I thank Christiane Nüsslein-Volhard (Max Planck Institute for Developmental Biology, Tübingen) for encouragement to write this piece, Enrico Coen (John Innes Centre, Norwich) for the picture of the wild-type and peloric Antirrhinum flowers, and Thiago Carvalho (Gulbenkian Institute of Science, Lisbon) for drawing my attention to the Darwin letter cited as reference [6].

\section{References}

I. Darwin CR: The Variation of Animals and Plants under Domestication. Volume 2. London: John Murray; 1868.

2. Mendel G: Versuche über Pflanzen-Hybriden. In Verhandlungen des naturforschenden Vereines in Brünn I865, IV:3-47. Brünn: Im Verlage des Vereines, 1866.

3. Darwin CR: On the Origin of Species by Means of Natural Selection. London: John Murray; 1859.

4. Darwin CR: The Effects of Cross and Self-Fertilisation in the Vegetable Kingdom. London: John Murray; 1876.

5. Darwin CR: The Different Forms of Flowers on Plants of the Same Species. London: John Murray; 1877.

6. Darwin Correspondence Project [http://www.darwinproject.ac.uk/ darwinletters/calendar/entry-4989.html]

7. Orel V: Gregor Mendel, the First Geneticist. Oxford: Oxford University Press; 1996.

8. Darwin F, Seward AC: More Letters of Charles Darwin. New York: D. Appleton; 1903.

9. Darwin CR: Charles Darwin's Essay of 1844. Edited by de Beer G. Cambridge: Cambridge University Press; 1958.

I0. Crick FH, Barnett L, Brenner S, Watts-Tobin RJ: General nature of the genetic code for proteins. Nature 1961, 192: I227-I 232.

II. Bateson W: Materials for the Study of Variation. London: Macmillan; 1894.

12. Huxley JS: Evolution, the Modern Synthesis. London: George Allen and Unwin; 1942.

13. De Vries H: Die Mutationstheorie. Leipzig: Veit; 190I-I 903.

14. Goldschmidt RB: The Material Basis of Evolution. New Haven: Yale University Press; 1940.

15. Eldredge N, Gould SJ: Punctuated equilibria: an alternative to phyletic gradualism. In Models in Paleobiology. T.J.M. Schopf edition. San Francisco: Freeman, Cooper and Company; 1972:82II5.

16. Bateson W: Mendels Vererbungstheorien. Leipzig and Berlin: B.G. Teubner; 1914.

17. Pearson K: The Life, Letters and Labours of Francis Galton. Volume 2. London: Cambridge University Press; 1924. 